\title{
Consideraciones científicas, éticas y legales a favor de la vida humana.
}

Francisco A. Laviada-Arrigunaga.

Clínica de Mérida, Mérida, Yucatán, México.

Como el tema: La vida humana desde su inicio, tiene interés permanente, sin pretender imponer un criterio personal, me parece conveniente razonar y meditar en relación a hechos científicos ya demostrados que sólo podrían generar controversia cuando existe diferente escala de valores.

No es sólo por temor a las complicaciones tanto físicas como mentales que derivan del aborto provocado que puedan argüirse como razonamientos en contra de su realización, sino que es cuestión de principios éticos y legales que corresponden a la dignidad de la especie humana. Estos principios se refuerzan con descubrimientos científicos.

Los siguientes párrafos están transcritos en forma casi literal y resumen los criterios de diferentes autores, estudiosos del tema, publicados en diversas revistas y tesis recepcionales que se mencionan en las referencias bibliográficas.

1.- Los conocimientos científicos de la Biología, de la Genética, de la Embriología, y de la Ingeniería Molecular son ya una evidencia experimental que conduce aceptar que la individualidad genética del óvulo fecundado, la continuidad de su desarrollo y la autonomía del proceso de formación del embrión, son hechos demostrados (1-5).

2.- En el huevo fecundado se reconstituye y define no sólo por el número de cromosomas característicos de la especie humana que lo determina desde entonces como persona y sujeto biológico, sino también, un particular y exclusivo patrimonio o código genético que lo determina en sus características individuales (1-4, 6).

3.- Existe, y lo ha demostrado la ciencia, una sola y absoluta continuidad en el proceso del desarrollo del embrión desde el momento de la fecundación hasta el nacimiento y después a la vida ulterior postnatal. Existe pues, materialmente presente en la estructura química del ADN un dinamismo continuo y unidireccional del proceso formativo, un verdadero programa de formación futura (código genético exclusivo para cada individuo). El conocimiento reciente del genona humano, reproducido en extraordinario y complejo

Solicitud de sobretiros: Dr. Francisco Laviada-Arrigunaga, Calle 35 No. 522 x 62 y 64, C.P. 97000, Mérida, Yucatán., México. 


\section{FA Laviada-Arrigunaga.}

mapa de las características genéticas de nuestra especie, apoya los conceptos antes mencionados $(2,3,5,8-10)$.

4.- También, la ciencia acepta y demuestra que el proceso de formación del embrión es autónomo. Aún cuando existe una íntima relación que se instaura entre el cuerpo de la madre y el hijo durante el período del embarazo, ofreciendo las condiciones materiales indispensables a la vida y al desarrollo del embrión y del feto después, que se desarrolla según un plan establecido y en virtud de un dinamismo autónomo autoregulando su propio desarrollo y los cambios hormonales en su hospedero. El ser hospedado en el seno materno vive una vida propia individual y autónoma (1-4).

5.- La moderna fenomenología y filosofía clásica definen el alma como "forma substancial" del cuerpo. Por más que sea distinta del cuerpo el alma constituye con el cuerpo un único ser: al que hoy llamamos "sujeto personal". La historia de nuestras vidas es la historia de nuestro cuerpo que tiene inicio en el momento de la concepción, de la cual según el psicoanálisis, sería posible encontrar las huellas en el inconsciente. Y como el término "persona" indica y expresa el valor que ontológicamente es propia de cada vida humana debemos decir, que la persona subsiste desde el momento en el cual se desarrolla la vida, o sea, desde la fecundación, por tanto, el ser que es producto de la concepción humana es desde el primer momento una persona, un hombre, por lo que el aborto puede calificarse como un auténtico homicidio $(2,4-6,8,10)$.

6.- Si nos apegamos a la moderna doctrina general del derecho, una vez que se establece netamente la diferencia entre personalidad jurídica y capacidad de actuar (o "capacidad de de goce y capacidad de ejercicio") el concepto de persona coincide con el sujeto de derechos; por lo que la única condición para ser sujeto de derechos es ser hombre. Concluimos, por tanto, que la idoneidad que para ser sujeto de derechos en términos generales, pertenece a todo hombre. Como consecuencia lógica está demostrado ya, que desde la concepción se trata de un ser humano, un sujeto personal que merece protección jurídica que tiene derecho a la vida y que es el presupuesto de todos los demás derechos (2,3,5,8-10).

7.- El Estado y el Derecho tienen razón de existir en la medida que hacen posible la mejor y la más segura convivencia humana respetando y protegiendo los valores y derechos de las personas en lo individual y en lo colectivo para el logro del bien común ya sea de un grupo social o de toda la humanidad (5,6,8-10).

Me complazco al verificar que en mi tesis recepcional sobre el aborto hace 51 años, sostuve los mismos argumentos morales para defender la vida desde su inicio, como lo hacemos ahora pudiendo contar con el refuerzo de los conocimientos científicos obtenidos en forma experimental (6).

Hago una invitación cordial, cualquiera que sea su escala de valores, a razonar con honestidad en relación con la dignidad de la vida humana, prerrogativa de nuestra especie: el embrión merece respeto irrestricto desde el inicio de su existencia.

Palabras clave: Embrión, código genético, ética médica.

\section{REFERENCIAS.}

1.- Romero A. Deontología Médica. La Formación de el Médico. Guadalajara: Ediciones Tlacuilo; 1964. p. 109121.

2.- Wilkie JC. Manual Sobre el Aborto. 12 Edición en Español. Cincinnati: Hiltz Publishing Co.; 1973.

3.- Anónimo. El Feto Humano es un ser que debe gozar de privilegios y tiene Derecho a la Vida. Diario de Yucatán. 1986 Dic 9.

4.- Roldán-González J. Etica Médica. Capítulo 19:Aborto y Derecho a la Vida. México: Librería Parroquial de Clavería; 3a. Edición. 1990. p. 211-31.

5.- Sada S. Razones por la Vida. El Aborto. Consideraciones para una Adecuada Reglamentación Jurídica. México: Proyección Mundial; 1991.

\section{Revista Biomédica}


6.- Laviada Arrigunaga Francisco A. El Aborto. Algunas Consideraciones Médicas y Sociales. Etiopatogenia del Aborto Espontaneo en Yucatán. Fac. de Medicina de la Universidad Autónoma de Yucatán. Mérida Yuc, Méx. 1949.

7.- Kuthy Porter J, De La Escosura G. Panorama bieótico en México. Bol Of Sanit Panam 1990; 108. p. 556-64.

8.- Calva-Mercado M, Vazquez-Aguilera O. Cap. 11: Estatuto Humano del Embrión. En Kuthy Porte. Introducción a la Bioética. México: Ed. Méndez Editores S.A. de CV; 1997. p. 137-151.

9.- Rendón-Bolio A. El Aborto (I-II). Las Leyes Yucatecas. Diario de Yucatán. 2000, Agosto.

10.- Goff Rendón CT. El Aborto. Problema Social. Abrogación del Artículo 315 del Código Penal Yucateco. Tesis en Opción al Título de Licenciado en Derecho. Fac. de Derecho de la Universidad Autónoma de Yucatán. Mérida Yuc. Méx. 1953. 